\title{
RELAÇÕES ECONÔMICAS, POLÍTICAS E EDUCACIONAIS NA CONSOLIDAÇÃO DO SENAI EM PONTA GROSSA, PR
}

\author{
Kelly Cristina Campones \\ Universidade Estadual de Ponta Grossa \\ kcampones@yahoo.com.br \\ Maria Isabel Moura Nascimento \\ Universidade Estadual de Ponta Grossa
}

\begin{abstract}
RESUMO
O texto trata das relações econômicas, políticas e educacionais da década de 40 no município de Ponta Grossa, PR, na busca de entendimento das causas da institucionalização do Senai neste contexto. Sabe-se que a educação profissional do Senai, veio por meio da Lei Orgânica, para atender as demandas da indústria e este sendo objeto de estudo ao longo da sua trajetória, uma vez que vem assumindo estratégias de apropriação do saber calcadas no interesse capitalista tornando-se desta forma, necessário obter clareza acerca das concepções e políticas educacionais adotadas.

O Senai de Ponta Grossa, teve sua origem em plena Segunda Guerra Mundial, momento este, de fragilidades econômicas e sociais. Desta forma, pretendemos apresentar as interfaces para tal institucionalização.

Palavras-chave: Ensino Profissional; Senai; História.
\end{abstract}

\section{THE ECONOMIC, POLITICAL AND EDUCATIONAL RELATIONS IN THE CONSOLIDATION OF SENAI IN PONTA GROSSA, PR}

\begin{abstract}
:
The text deals with the political, educational and economic relations during the 40s in the municipality of Ponta Grossa - PR with the objective of understanding the causes leading to the institutionalisation of the Senai in this municipality. It is historically known that the professional education of Senai came officially through the Organic Law, with the objective to respond with courses developed in the short term to meet the industrial demands. This has been an object of relevant study along its trajectory, since it has been assuming strategies of knowledge appropriation based on the capitalist interest becoming this way necessary to outline the conceptions and educational politics adopted. Senai Ponta Grossa, had its origin during the Second World War, a time of economic and social weaknesses. This way we intend to present the historical interfaces for such institutionalization.
\end{abstract}

Key words: Professional Education; Senai; History 


\section{Introdução}

Para a criação do Serviço Nacional de Aprendizagem Industrial em Ponta Grossa, PR existiram fatores econômicos, políticos e sociais que culminaram com a sua institucionalização. Isto porque, as bases econômicas passavam de uma atividade em que estavam voltadas à agricultura, para um período econômico de expansão das indústrias, do comércio e da consequente diversidade nas mediações sociais.

A cidade de Ponta Grossa, PR, historicamente oriunda da tradição tropeira, a qual regionalmente caracterizou-se por,

[...] estar no caminho das tropas, foi se organizando economicamente pela atividade pastoril, servindo também de passagem de "invernagem" do gado que ia ser vendido na feira de Sorocaba. As fazendas, [...] foram se formando nos Campos Gerais, juntamente com a abertura dos Caminhos, organizando e realizando atividades de subsistência dos Campos Gerais (NASCIMENTO, 2008, p 29).

A atividade antes pastoril - voltada à sobrevivência e a comercialização de animais - experimentava, no início do século XX, um movimento econômico diferente, voltado à iniciativas industriais, pois, com o processo imigratório, houve consequentemente um intenso crescimento regional intensificado pela economia estabelecida na produção ervateira e madeireira.

A composição étnica da cidade era bastante diversificada. Historicamente, os primeiros imigrantes foram os russos-alemães ${ }^{1}$, os quais se instalaram principalmente no atual bairro da Nova Rússia.

Além dos russos- alemães, também se destacavam a presença dos poloneses. Curitiba era a cidade preferida deles, no entanto, havia registro desses, nas cidades de Mallet, Ponta Grossa, São Mateus, Prudentópolis, Irati, Ipiranga, Guarapuava e União da Vitória (PADIS, 2006).

Nas representações discursivas noticiadas no jornal local da época, pode-se elencar alguns fatores que propiciaram para que as diversas etnias fossem atraídas a instalar-se em Ponta Grossa, PR, pois,

[...] pela situação, pela sua altitude, goza de raros privilégios sobre outras tantas localidades não do Estado, como do paiz. Clima ameno...,execelentes estabelecimentos de ensino...,vida relativamente barata...,admirável ordem pública...,povo lhano e hospitaleiro...,higiene e limpeza pública impecável...[Por isso] homens laboriosos têm escolhido Ponta Grossa...para fixar suas residências (DIÁRIO DOS CAMPOS, 18 de fevereiro de 1937).

As boas condições climáticas e regionais e a aparente organização local, bem como o custo baixo de vida, favoreceram a vinda e a permanência de outros povos.

Acrescenta-se ainda, que muitas outras etnias já se encontravam nessa região, entre elas, sírios libaneses, espanhóis e italianos, os quais, "[...] foram se organizando e fundando pequenas indústrias, de acordo com o conhecimento que traziam" (NASCIMENTO, 2008, p.108, grifos do autor).

Sabendo que o ensino profissional preconizado pelo Senai era voltado para a qualificação profissional da força de trabalho necessária nas indústrias, faz-se necessário considerar os aspectos econômicos, políticos e sociais que implementaram e mostraram as 
necessidades da criação da referida instituição de ensino profissional no município de Ponta Grossa.

\section{O cenário econômico, político e social para a criação do Senai}

Ponta Grossa, PR, é um município localizado estrategicamente, pois, territorialmente liga-se a São Paulo, Santa Catarina e Rio Grande do Sul e "[...] tornou-se, a partir da Estrada do Viamão, o maior entroncamento rodo ferroviário do Sul [...]" (TREVIZAN, 1995, p. 48).

Essa situação de entroncamento ferroviário,

[...] fêz com que Ponta Grossa entrasse no século XX com o pé direito. [...] Grandes engenhos de erva-mate, beneficiamento de couro e de madeira começaram a surgir. E olarias pois não havia tijolo que chegasse. Veio gente de fora atraída pela promessa de bons negócios (WANKE, 1964, p.76).

A configuração urbanística da cidade se amplia na medida em que os imigrantes já estabelecidos no Brasil e os que chegavam, buscavam novas oportunidades mercadológicas e acreditavam que em Ponta Grossa, poderiam encontrar grandes oportunidades de negócios.

Outro fator a se considerar, foi o advento da instalação da Estrada de ferro do Paraná e Estrada de Ferro São Paulo - Rio Grande, o qual trouxe a dinamização de alguns setores da economia, mudanças na infraestrutura da cidade e o consequente aumento do número de residências, causando inclusive, um comportamento cultural diferente nas pessoas.

Além do desenvolvimento industrial e comercial, provocado pela vinda e permanência dos imigrantes citados, bem como pelas instalações das ferrovias, as quais trouxeram um modelo diferente de organização na estrutura civil e grande movimentação nas perspectivas econômicas, políticas e educacionais, a cidade de Ponta Grossa, PR, viveu-se um grande marco, pois, em 03 de maio de 1905, a luz elétrica foi inaugurada na cidade. Essa vinda de energia elétrica para a cidade "[...] atua como fator de aumento da divisão do trabalho dentro da sociedade e torna mais estreitos os laços de dependência de cada unidade social em relação às demais" (SILVA, 2001, p. 96).

A instalação da estrada de ferro e a ocupação urbana por outros povos, bem como a instalação de energia elétrica, foram consideradas os principais fatores da expansão comercial e populacional, sofrida nas primeiras décadas do século XX, em Ponta Grossa, pois "[...] parte da ocupação habitacional aconteceu nas margens das linhas férreas e nas proximidades dos equipamentos da rede [...]” (DITZEL; SAHR, 2001, p.40).

Essa expansão propiciou mudança no urbanismo e na economia da região. Com a utilização da ferrovia, os trens que vinham de outros locais realizavam cargas e descargas de vários produtos a serem comercializados na região.

Ponta Grossa foi escolhida para

[...] a implantação de infra-estrutura que atendeu aos interesses da Companhia: pátios para manobras e armazenamento de comboios, oficinas de locomotiva e vagões, estações de cargas e passageiros, depósitos de vagões, locomotivas e cargas, usinas de tratamento de dormentes e trilhos, além de escolas profissionalizantes, hospitais, armazéns e vilas operarias (DITZEL; SAHR, 2001, p. 40 grifos do autor). 
Essas instalações configuraram o processo de crescimento urbano da cidade, gerando inclusive, um novo ramo de atividade profissional para os trabalhadores e ofertas de empregos advindas para essa classe ferroviária. Nesse ínterim, houve a necessidade de instituir um ensino profissionalizante para atender a implantação dessa infraestrutura.

Com a ferrovia,

[...] surgiram também alguns bairros como o de Oficinas, que reunia as instalações de conserto e manutenção de vagões, e o Cara-Cará, que se desenvolveu a partir da usina de tratamento de dormentes ${ }^{2}$ e da pequena estação de trens ali existentes (DITZEL, 2007, p.58).

O surgimento de alguns bairros em Ponta Grossa, PR, deve-se pela participação na consolidação e no término da construção da estrada de ferro, onde se verificou que houve a participação de outras etnias, principalmente, russos- alemães e poloneses, os quais foram se estabelecendo ao longo das linhas férreas e aumentando a população do município.

Em "[...] 1906 era inaugurada [oficialmente a estrada de ferro] e os seus trens corriam ligando São Paulo ao Rio Grande, passando pelo Paraná e Santa Catarina" (HOLZMANN, 1975, p.28) trazendo produtos tais como: erva mate, alimentos, madeiras, louças, medicamentos e outros, para a comercialização local.

A ferrovia gerou modificações no contexto social da cidade de Ponta Grossa, PR, em função da cidade,

[...] compor a malha ferroviária, sendo um importante entreposto comercial e parada obrigatória dos trens que vinham de Curitiba e dos que circulavam entre São Paulo e Rio Grande do Sul, com extensão ao Uruguai e Argentina, foi criada, próximo à Estação Ponta Grossa (estação de passageiros), uma infra-estrutura para atender aos visitantes, composta de hotéis, pensões, bares, restaurantes, lojas de varejo, além daquelas edificações destinadas às cargas, com depósitos, armazéns (DITZEL ; SAHR, 2001,p.43).

As práticas econômicas vigentes, nesse período, os conceitos e as necessidades sociais trazidos pelos imigrantes e a possibilidade de um deslocamento mais rápido de produtos, trouxeram uma mobilização social que se traduziu em um crescente movimento mercadológico.

Ponta Grossa, no início do século XX, apresentava devido a esse "crescimento", uma estrutura social onde, pelas

[...] ruas, movimenta-se gente em grande porção. Ás lojas entram e saem cavalheiros e senhoras [...] Nas grandes casas comerciaes o trabalho é enorme porque delas se abastece todo o interior do Estado. O movimento urbano ultrapassa o tamanho da cidade. Vê-se gente por toda a parte $(\mathrm{O}$ Progresso, 20 de julho de 1912).

As descrições das características das pessoas que estavam na cidade projetavam-na e a mostravam como um município em acentuado processo de expansão e consequentemente, de ampliação das necessidades de atividades industriais e comerciais, para suprir a demanda existente.

Sobre a infraestrutura da cidade de Ponta Grossa, PR, em 1911 iniciou os serviços voltados à telefonia e a partir de 1912, o processo de construção da rede de esgoto e água. 
De acordo com o censo de 1920, os habitantes chegaram a "[...] 20.171 habitantes, consolidando-se como a maior cidade do interior paranaense [...]" (CHAVES; BREMBATTI, 2008, p.13). Para atender as diversidades sociais e a nova realidade urbana, foram formadas inúmeras instituições e organizações associativas, tais como: clubes sociais, sociedades operárias, partidos políticos, entre outros.

Esse processo de tentativa da organização da sociedade resulta em "[...] uma estrutura social dividida entre os que são os proprietários dos meios de produção e os que detêm apenas a força de trabalho, que a vendem para sobreviver" (MARTINS, 1969, p. 42). Ou seja, cada organização ou instituição criada atendia as expectativas de um determinado interesse social.

Em meados de 1920, a organização da cidade,

[...] já era mais "próspera" cidade do interior do Paraná, pois contava com equipamentos incomuns para a época: calçamento, telefone, água encanada, rede de esgoto, hospital e possuía uma vida cultural intensa (DITZEL; SAHR, 2001, p.45).

Estes fatores propiciaram e consolidaram, durante as quatro primeiras décadas do século XX, a instalação de várias indústrias e comércios em Ponta Grossa, nas quais, estavam assim estruturadas:

[...] dos 1.632 estabelecimentos industriais existentes em todo Estado, 75 estavam fixadas em Ponta Grossa, ou seja 5,5\% do total das indústrias registradas. Comparando com números referentes a outras cidades do Estado, [...] Curitiba possuía 535 indústrias $(39,3 \%), 32$ indústrias se situavam em Paranaguá $(2,3 \%)$ e Guarapuava contava com 22 estabelecimentos industriais $(1,6 \%)$ (CHAVES, 2006, p. 34, grifo nosso).

Ponta Grossa, PR, estava com um número expressivo de indústrias fixas. Nos setores do comércio e da indústria, detalhadamente, tinha:

[...] 7 fábricas de carnes (conserva), 1 de cerveja, 7 de móveis, 19 de café, 3 de móveis, 1 de pregos, 3 de doces, 2 de massas alimentícias, 23 de roupas, 9 de cal, 4 de sabão,36 de farinha, 2 de laticínios, 2 de tintas, 6 de calçados, 6 de bebidas alcoólicas, 15 de ferragens; além de 14 serrarias, 3 curtumes, 9 olarias, 4 marcenarias, 10 carpintarias, 6 funilarias, 16 ferrarias (DITZEL e SAHR,2001,p.42).

Considerando o potencial deste município, percebe-se porque a cidade de Ponta Grossa, PR, estava citada, nos relatórios do Departamento Regional do Senai, como um dos locais de instalação da sua escola profissional.

A ideologia para tal criação, também pode estar baseada nos discursos que a instituição trazia de que, a educação profissional estabelecia uma conexão rápida e eficaz com as necessidades das empresas.

Com a expansão da cidade, acredita-se que o Estado - institucionalizando o ensino profissional na região - demonstraria a intencionalidade ideológica da manutenção de uma cultura de estar colaborando com a empregabilidade da classe trabalhadora nos estabelecimentos industriais, por meio da implantação da formação profissional.

A cidade ponta-grossense era percebida como um importante centro econômico do interior do Estado do Paraná. No âmbito destas relações com outros locais, aos poucos 
[...] centros maiores, como Curitiba, Porto Alegre, São Paulo, Recife, Belém, Rio de Janeiro, Buenos Aires e Montevidéu, passaram a compor o rol de mercados abastecidos por produtos saídos de Ponta Grossa (CHAVES; BREMBATTI, 2008, p.21).

Com a economia em expansão, houve a necessidade de instalar, também, agências bancárias. $\mathrm{Na}$ "[...] década de 1920, a cidade já contava com quatro casas bancárias: Banco do Brasil, Banco Francez e Italiano, Banco Nacional do Commércio e Banco Pelotense" (CHAVES, 2006, p.34) e em 1922, fundou o Centro Commércio e Indústria (CCI), cuja prioridade era defender os anseios e necessidades dos empresários locais.

Desse modo, elencam-se algumas indústrias que existiram em Ponta Grossa, onde, proprietários e/ou trabalhadores, posteriormente, procurariam uma apropriação de conhecimento, direcionada em escola profissional.

Entre elas estão:

Quadro 1- Algumas indústrias do século XX em Ponta Grossa

\begin{tabular}{|c|c|c|c|}
\hline Nome da fábrica & Proprietário & Ano & Descrição \\
\hline $\begin{array}{l}\text { Fábrica de Fogos } \\
\text { São Pedro }\end{array}$ & $\begin{array}{l}\text { Sr. Pedro } \\
\text { Barbosa }\end{array}$ & 1922 & $\begin{array}{l}\text { Fornecia fogos de sinalização para o serviço de } \\
\text { trem. }\end{array}$ \\
\hline $\begin{array}{l}\text { Cia. Industrial } \\
\text { Mercedes }\end{array}$ & $\begin{array}{l}\text { Sr. Ewaldo } \\
\text { Kossatz }\end{array}$ & 1920 & $\begin{array}{l}\text { Fábrica de parafusos, pregos, dobradiças, rebites, } \\
\text { arruelas, prensas, etc. Fazia importação e exportação } \\
\text { de seus produtos. }\end{array}$ \\
\hline $\begin{array}{l}\text { Hervateria } \\
\text { Pontagrossense }\end{array}$ & $\begin{array}{l}\text { Sr.José } \\
\text { Pompeo }\end{array}$ & $\begin{array}{l}\text { Início do } \\
\text { século XX }\end{array}$ & $\begin{array}{l}\text { Além de comercializar erva mate, inaugurou no } \\
\text { mesmo espaço uma serraria e uma fábrica de caixas. }\end{array}$ \\
\hline Serraria Olinda & $\begin{array}{l}\text { Sr. Theodoro } \\
\text { Kluppel }\end{array}$ & 1906 & $\begin{array}{l}\text { Fábricas de caixas e depósito de madeiras. Possuía } \\
\text { aproximadamente } 80 \text { trabalhadores. }\end{array}$ \\
\hline $\begin{array}{l}\text { Marcenaria } \\
\text { Pinkowski }\end{array}$ & $\begin{array}{l}\text { Sr.Bolis } \\
\text { Pinkowski }\end{array}$ & $\begin{array}{c}\text { Início do } \\
\text { século XX }\end{array}$ & Fábricas de mobílias. \\
\hline $\begin{array}{l}\text { Indústrias } \\
\text { Pharmaceuticas } \\
\text { Pontagrossenses }\end{array}$ & $\begin{array}{l}\text { Sr.Octaviano } \\
\text { de Macedo } \\
\text { Ribas }\end{array}$ & $\begin{array}{l}\text { Início do } \\
\text { século XX }\end{array}$ & $\begin{array}{l}\text { Produzia nos laboratórios: vermífugos, essências, } \\
\text { bálsamos, elixir, xarope e pílulas. Instalado na Rua } \\
\text { Marechal Deodoro. }\end{array}$ \\
\hline
\end{tabular}

Fonte: autora apud Chaves (2006).

Nesses locais, como nas demais indústrias brasileiras, os proprietários utilizam-se da força de trabalho coletivo, apropriando-se, simultaneamente do lucro originado pelos mesmos.

$\mathrm{Na}$ atividade industrial ponta- grossense, considerou-se como uma das fábricas que mais se destacou e teve longa permanência na região foi a Cervejaria Adriática, fundada por Henrique Thielen.

Sobre o movimento econômico dessa empresa, percebeu-se que rapidamente,

[...] as bebidas, cervejas e gasosas, produzidas por Thielen, inseriram-se nos mercados do Paraná, Santa Catarina, Rio Grande do Sul e São Paulo. Com o passar dos anos, os produtos da Cervejaria Adriática conquistaram mercados mais distantes, sobretudo no Norte e Nordeste brasileiro e em alguns pontos da Europa (CHAVES, 2006, p.31). 
Com a expansão nacional do produto dessa fábrica, existiu a necessidade de aumentar a força de trabalho e no final da primeira década do século XX, contava com 120 operários e um depósito na capital do Estado do Paraná.

A Cervejaria Adriática configurou-se como uma das principais indústrias da região de Ponta Grossa, por permanecer em funcionamento durante aproximadamente 40 anos. Vale ressaltar que, foi também, uma das empresas que, posteriormente, fez parceria com o Senai no acolhimento dos alunos que necessitavam de espaço para suas aulas práticas.

Caracterizou-se pelo investimento constante em maquinários e na qualificação de seus mestres cervejeiros, inclusive "[...] enviando muitos deles para aprender as técnicas de produção das principais cervejarias da Alemanha" (CHAVES; BREMBATTI, 2008, p.25).

A cervejaria qualificava sua força de trabalho em outro país, pois, inexistia, naquele momento, uma instituição de formação profissional, para atender este segmento.

Sobre outras indústrias, destacaram-se, também, as direcionadas ao setor madeireiro e seus derivados, que se apresentavam na região como um ramo promissor de comercialização, pela existência de muitas serrarias.

A indústria de transformação constituiu-se como a principal atividade econômica da população, sendo que a de madeira representava 39\% do valor das demais, "[...] São 122 estabelecimentos industriais ocupando 2.940 pessoas, das quais 2.402 eram operários" (DITZEL, 2007, p. 70).

A cidade, entre 1920-1945, contava com 38.417 habitantes, dos quais 74,5\% estavam no meio urbano. Era considerada a cidade com o maior número de habitantes que viviam nas cidades, enquanto Curitiba possuía na mesma época, apenas $50 \%$ de urbanização (DITZEL, 2007).

Na imagem, a seguir, identifica-se, “[...] os trilhos da ferrovia e as chaminés das fábricas [que] simbolizam a pujança econômica de Ponta Grossa em meados do século XX” (CHAVES; BREMBATTI, 2008, p.53).

Figura 1- Ponta Grossa na década de 40

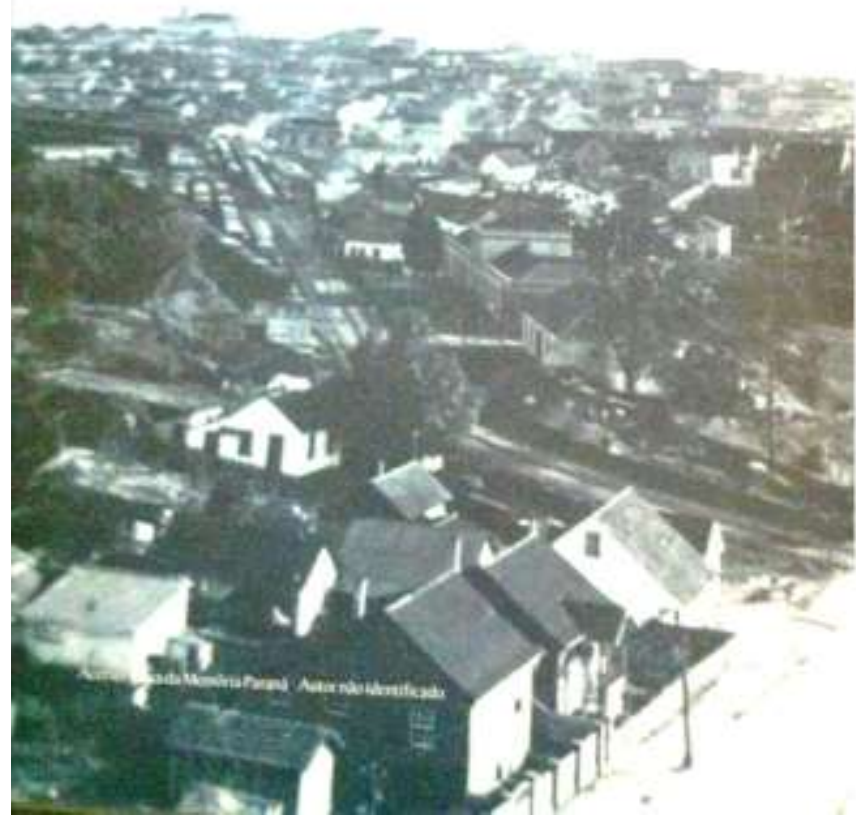

Fonte: Casa da Memória Paraná - autor não identificado apud CHAVES;BREMBATTI, 2008,p.53. 
Nesse período houve redução considerável da produção de erva mate, o que levou o governo estadual a criar estratégias políticas, promovendo uma redução de vinte por cento nas taxas de importação, com a expectativa de reverter a situação. No entanto, essa ação não foi suficiente para desenvolver a ideia do consumo do mate pelos brasileiros.

O desenvolvimento das cidades, organizadas segundo políticas pré-estabelecidas, de forma geral, já condicionava as relações sociais e consequentemente, as de trabalho, em estabelecer novos critérios e formas de organizar-se. Nessa perspectiva, a educação também estaria ligada a este processo, como

[...] uma agência educativa ligada às necessidades do progresso, às necessidades de hábitos civilizados, que corresponde à vida nas cidades. E a isto também está ligado o papel político da educação escolar enquanto formação para a cidadania, formação do cidadão. Significa formar para a vida na cidade, para ser sujeito dos direitos e deveres na vida da sociedade moderna, centrada na cidade e na indústria (SAVIANI, 1994, p.153).

De forma geral, as relações educacionais estabelecidas na sociedade capitalista, em relação à qualificação para atender a vida em sociedade, adquirem uma maior proporção, na medida em que esta vem consolidar a força de trabalho necessária para a produção da mais valia.

Identifica-se que a história do capitalismo é a própria combinação da força de trabalho e do assalariamento como condição de reprodução do próprio capital, por isso, "[...] é a história da acumulação do capital e da apropriação da mais-valia, que acontece tendo como pano de fundo a luta de classe intrínseca e permanente às relações de produção" (GOMEZ et al.,1995, p. 48).

No campo das ideias, os industriários acreditavam que, por meio da qualificação teórica e prática dada nas escolas profissionais, o indivíduo seria capaz de resolver os problemas profissionais, além de produzir mais e melhor.

Nas relações entre trabalho e educação, o Estado cria as produções do conhecimento profissional sistematizado pela classe dominante, a qual conduz de forma desigual às condições do saber nas classes trabalhadoras.

No município de Ponta Grossa, como nos demais municípios dos Estados brasileiros, a sistematização do conhecimento para os trabalhadores das indústrias, foi monopolizada pela classe social que detinha os instrumentos materiais para tal ação.

Como práxis social, é preciso pensar que a ideologia passada pelo Estado corresponde a atividade educacional, pois, caracteriza-se como um processo educativo profissional, desigual e contraditório, que acaba, na maioria das vezes, por aniquilar a identidade dos trabalhadores.

Dessa forma,

[...] o direito à educação, os avanços das classes trabalhadoras na formação do saber, da cultura e da identidade de classe continuam sistematicamente negados, reprimidos e, enquanto possível, desestruturados, por serem radicalmente antagônicas ao movimento do capital (GOMEZ et al.,1995, p.78).

Historicamente, percebe-se que toda ação que sintetize o direito a educação para a classe trabalhadora, tornou-se instrumento de contradição, pois, ela apresenta os interesses particulares de uma determinada classe social. Seus discursos camuflam esses interesses e 
procuram apresentá-los como se fossem interesse da maioria da classe trabalhadora. Essa estratégia de impedir o aprofundamento do conhecimento sistemático, na sua totalidade, apenas reafirma a manutenção considerada vital no mundo capitalista.

Lembremo-nos, entretanto, que - numa fase anterior a vinda do Senai - existiram no município de Ponta Grossa, algumas iniciativas voltadas à educação profissional, a fim de atender as indústrias que estavam se instalando e as demandas geradas pela estrada de ferro.

\section{Institucionalização do Senai no Município de Ponta Grossa, PR}

As atividades de formação profissional do Senai, em Ponta Grossa, têm início em 1943, em plena Segunda Guerra Mundial. A ausência de importações e a intensidade na demanda de produtos minerais e da indústria de transformação elevavam, consideravelmente, esse setor em todo o Brasil e, consequentemente, passava a necessitar a cada dia, de um maior número de trabalhadores qualificados.

Ponta Grossa também sofria os aspectos relativos ao período de guerra, pois, neste período, houve oscilações na produção e dificuldades econômicas. "[...] quase todas as atividades de natureza comercial, industrial, financeira e de transporte acham-se subordinadas ao controle e aos interesses das autoridades federais, estaduais e municipais" (CHAVES; BREMBATTI, 2008, p.49).

Neste ínterim, o Senai no município de Ponta Grossa, iniciou suas atividades como

[...] uma Agência de treinamento, situado no Edificio Comercial a rua Coronel Claudio, tendo como agente de treinamento Arinaldo Gobbo, e como secretário o professor Orual Nemézio Boska, o qual tornou-se mais tarde diretor da Escola e Centro Técnico de Celulose e Papel de Telêmaco Borba(Casa da Memória- autor desconhecido).

Em 1943, para atender a Agência de Treinamento do Senai, em Ponta Grossa, foram selecionados pessoas para preencher o corpo técnico, formadas nos ofícios de Mecânica Geral, Eletricidade, Ferreiro e Marceneiro pela Escola Ferroviária Tibúrcio Cavalcanti, a qual, conforme já verificamos, era uma escola pertencente a RFFPRSC Rede Ferroviária Federal Paraná- Santa Catarina, que também visava a formação de pessoas em vários ofícios, porém, destinadas a manutenção principalmente da malha ferroviária regional.

A locação de imóveis para dar início às atividades do Senai, não foi diferente no município de Ponta Grossa. A sua institucionalização, deu-se por meio do uso de imóveis locados. Sobre estes espaços, especificamente, consta que

[...] as aulas ministradas em salas alugadas [aconteciam] onde era o Colégio Regente Feijó e Escola Normal, atualmente é o Centro de Cultura Cidade de Ponta Grossa. Depois foram alugadas salas no Grupo Escolar Julio Teodorico e mais tarde na Academia Comercial Pontagrossense, SEPAM e também na sala da Associação Comercial e Industrial (Casa da Memória- autor desconhecido).

As negociações para locação de tais espaços foram feitas pelo professor Lourival Sponholz.

O Diretor Regional do Senai no Paraná, Flausino Mendes, determinou que o professor Trevisan, que já havia conduzido cursos profissionais na Escola Ferroviária 
Tibúrcio Cavalcanti, assumisse a organização do funcionamento do Senai em Ponta Grossa. Diante desta nomeação, Flausino Mendes logo tratou de implementar diversos cursos. (Casa da Memória- autor desconhecido).

Sobre esses cursos, havia os noturnos, os quais possuíam um caráter de aperfeiçoamento profissional, sendo ofertados para as pessoas que trabalhavam nas fábricas ou no comércio com o objetivo principal de atender as necessidades que as empresas tinham, naquele momento.

Os diurnos foram denominados de Curso de Aprendizagem de Ofício (CAO), os quais se destinavam aos menores de idade entre 14 e 16 anos, com aulas teóricas no período da manhã e a tarde funcionava dentro das empresas com aulas práticas ou "[...] uma semana na empresa, outra semana na escola; ou mês numa, mês noutra" (CUNHA, 2000, p.62).

Para que ocorressem estas aulas, fez-se necessária parceria com empresas, e em Ponta Grossa, as

[...] que mantinham a aprendizagem com o Senai eram: Cia Prada e Eletricidade, Cervejaria Adriática, Mecânica Industrial Brephol, Ford, Cornélio de Geus, Viação Campos Gerais (antigo Expresso Mezzomo Departamento de Estradas de Rodagem do Paraná) ( Casa da MemóriaAutor desconhecido).

Desta forma, ao articular ações pedagógicas de cunho teórico fundamentado nas Séries Metódicas, com as atividades práticas desempenhadas por essas empresas, acreditava-se que se "[...] pretende [ou pretendia] formar um corpo coletivo qualificado na medida exata das suas necessidades e politicamente submisso e disciplinado" (KUENZER, 2002, p.189).

Ainda, neste sentido, os discursos relatavam que

São as necessidades e as condições da produção que ditam como deve ser feita a formação. São as mudanças e inovações da técnica industrial que determinam alterações nos métodos da Escola. É a possibilidade de emprego em determinados ofícios que deve orientar a ampliação do número dos respectivos aprendizes. São os efeitos notados no trabalho que sugerem correção no período de aprendizagem (LOPES, 1982, p.51).

Atreladas às necessidades de produção capitalista o Senai buscava, no desenvolvimento do CAO, sua aproximação e manutenção com seus pares garantindo desta forma, também a reprodução social.

Além desses cursos, havia: Cursos Rápidos de Formação (CRF) e o de Leitura e Interpretação de Desenho, os quais formaram rapidamente 78 alunos, em 1943. (Casa da Memória - autor desconhecido).

A maior procura, porém, estava nos CAO e nos cursos de Aperfeiçoamento em mecânica e mobiliário. Para sua aplicabilidade, a Delegacia Regional contratou o primeiro professor Arinaldo Lucy Gobbo, o qual tinha função de supervisor e de gerente de treinamentos. Ele ensinava um trabalhador da indústria para auxiliá-lo na supervisão das aulas práticas dos alunos.

Outros foram contratados, também como professores: Raul Machado, que além de ministrar aula de Matemática, foi contratado para o cargo de diretor geral, Edgar Zanoni, Lídia Kubiak Mildrede Franco, Orual Nemézio Boska e os técnicos Eugênio Alves, Luís Lourenço; Marcos Tozetto, José Victor Ceregato, Dario de Oliveira, Angelo Kochmann, 
Wilson Tozetto, Arinaldo Gobbo e José Edson Roche, para ensinar nos períodos diurnos e noturnos (TREVIZAN, 1995).

Na contratação do professor Luis Lourenço, utilizou-se sua residência, situada na Rua: Judith da Silveira, $\mathrm{n}^{\mathbf{0}}$ 92, no bairro de Olarias, como sede do primeiro escritório do Senai em Ponta Grossa, funcionando por aproximadamente 20 anos (Casa da Memóriaautor desconhecido).

$\mathrm{Na}$ organização da rotina docente, havia a escolha entre eles, de um "professorchefe", o qual era contratado por hora de ensino e tinha também, as seguintes funções:

a) fiscalização do trabalho dos professores;

b) visar, pelo menos uma vez por semana o "plano semanal de lições" e o diário de lições;

c) manter em dia o registro de notas mensais e o boletim de alunos;

d) remeter até o último dia de cada mês o rumo de notas e frequiência;

e) manter em dia o livro de carga de materiais;

f) dar conhecimento imediato sobre alunos que ultrapassam de 10 faltas em qualquer disciplina;

g) requisitar os materiais necessários aos cursos;

h) remeter até o dia 25 de cada mês o ponto do pessoal

i) remeter toda segunda-feira, o boletim dos alunos, com o ponto da semana, para ser vistado pelo empregador ( Casa da Memória- autor desconhecido).

Essa concepção de "professor-chefe" remete-se em aproximar o ensino profissional preconizado pelo Senai com a forma de organização das indústrias, ou seja, além das atividades características de um docente como o preenchimento do livro de registro, organização didática, caberia controlar o "ponto" dos alunos bem como o trabalho dos seus pares. Assim, a "[...] estratégia da burguesia parece ser entregar a instrução do povo aos educadores profissionais no sistema escolar desde que ela mantenha o controle de sua escola de fabricar o trabalhador" (GOMEZ et al.,1995,p. 90).

A estratégia administrativa de destacar um "professor-chefe"

[...] contêm um projeto pedagógico explícito, na medida em que objetivam educar o trabalhador para o processo produtivo racionalmente organizado, com mecanismos de controle e de difusão da ideologia conveniente aos interesses do capital (KUENZER, 2002, p. 67).

Comparando com os relatos escritos anteriores sobre, o papel do professor do Senai, observou-se que, somente na Agência de Treinamento do Senai em Ponta Grossa, é que existiu agregação contratual de docente com papel também de "chefe".

A falta de uma sede própria trazia, também, algumas dificuldades, pois,

[...] os funcionários (professores) tinham que se deslocarem de bicicleta diariamente de empresa por empresa para fiscalizar os trabalhos e orientar os alunos. Os materiais utilizados nas aulas eram estocados na casa de algum professor. Os materiais de Mecânica Industrial eram guardados na casa do professor Gobbo, que também era instrutor de ofícios, o qual separava os pedidos e distribuía nos dias das aulas nas empresas ao mesmo tempo que supervisionava a aprendizagem, chegando a dedicar-se 20 a 30 minutos por aluno [...] (Casa da Memória- autor desconhecido). 
Identifica-se, portanto, que para um adequado desenvolvimento das aulas práticas, teria que haver, por parte dos docentes, a tarefa adicional no deslocamento e otimização do material didático, além do que, "[...] os instrutores eram obrigados a usar gravatas, mesmo durante o treinamento de alunos nas oficinas" (TREVIZAN, 1995, p.48).

Nos cursos do CAO, assim como nos outros Estados brasileiros onde o Senai foi institucionalizado, o controle dos aprendizes nas aulas práticas era registrado por pessoas da indústria, por meio de carteirinhas.

Para os cursos de Aperfeiçoamento noturnos, destinados ao público adulto,

[...] foram contratados instrutores da Escola Profissional Ferroviária Cel. Tibúrcio Cavalcanti, em virtude de sua experiência no emprego da metodologia do ensino técnico, em que foram treinados e orientados por competentes técnicos de formação profissional do Centro Ferroviário de Ensino e Seleção Profissional da Estrada de Ferro Sorocaba, conveniada com a Rede de Viação Paraná - Santa Catarina e responsável pela instalação e pela introdução do primeiro programa de formação profissional racional do Estado do Paraná (TREVIZAN, 1995, p.49).

Por meio de uma metodologia pragmatista, a modelagem para que ocorresse a aprendizagem profissional tinha como elementos fundamentais as experiências anteriores e uma escola profissional com metodologia racional, a fim de tornar os indivíduos em cidadãos "capazes".

Todavia, entende-se que qualificar pessoas para o trabalho industrial vai além de torná-las "capazes". Existe um contexto social mais amplo que, muitas vezes, revela um caráter discriminatório, então, a "[...] transição da sala de aula à fábrica ou a oficina processa-se facilmente para quem aprendeu que não pode tomar decisões por si próprio e nem confiar em si, que necessita estar sob tutela" (OLIVEIRA, 2001,p.27).

Com relação à execução teórica dos cursos, assim como nos outros locais onde se instituiu o Senai, utilizou-se como padrão de ensino, os materiais didáticos baseados nas Séries Metódicas Ocupacionais. Estas apostilas de ensino padronizadas para desenvolver o trabalho nas indústrias não consideravam as diversidades dos trabalhadores. Ademais, sendo uma "[...] entidade de âmbito nacional [...] o Senai, logrou alcançar um alto grau de padronização dos métodos de ensino, assim como da nomenclatura" (CUNHA, 2000, p.67).

Nesse sentido, para o trabalho pedagógico do professor

[...] fragmentado, respondeu, e continua respondendo, ao longo dos anos, às demandas de disciplinamento do mundo do trabalho capitalista organizado e gerido segundo os princípios do taylorismo/fordismo, em três dimensões: técnica, política e comportamental (KUENZER, 2002, p. $85)$.

O modelo padrão de material didático adotado em todos os Estados brasileiros gera, nesta pesquisa, uma inquietação, principalmente, no que diz respeito às condições que se tinham em cada escola do Senai, pois, as demandas de cada local eram diferentes, bem como, a diversidade de público.

No entanto, nem todos os professores que trabalhavam em prol das demandas do mundo capitalista industrial tinham a consciência da fragmentação do seu trabalho. Cunha 
(2000), ao entrevistar alguns professores, identificou aqueles que defendiam tal ação pedagógica para o desenvolvimento dos cursos do Senai, e concluiu que

[...] essa metodologia de ensino foi necessária ao início do Senai, quando os instrutores tinham de ser improvisados e a cultura industrial era ainda incipiente no país [...] os próprios instrutores nada mais eram do que executores de tarefas. Com as séries metódicas ocupacionais, o Senai garantiu um conteúdo mínimo em todos os cursos de aprendizagem de cada especialidade. Ademais, as atitudes que a ela correspondiam eram as da disciplina fabril, adequadas ao momento em que a industrialização se iniciava no país (CUNHA, 2000, p.77).

O papel dessa metodologia era adaptar os indivíduos para o trabalho nas máquinas e ferramentas e ensinar-lhes o mínimo para que se mantivessem trabalhando. Bologna (1980, p.324, grifos do autor) destaca que:

[...] o Senai está precisamente ensinando ao trabalhador brasileiro a trabalhar melhor; está concorrendo para que, ano por ano, o nosso trabalhador, sabendo trabalhar melhor, vá aumentando sua produção, a ponto de vir a ser o trabalhador que melhor produza, Essa, a meta.

Pode-se inferir que, a produção material industrial a serviço do capital como resultado da metodologia adotada é uma estratégia que culmina na subordinação do trabalho; na extração de mais-valia e de controle do processo produtivo (Taylorismo e Fordismo).

No decorrer do tempo, tornou-se algo a ser discutido, pois, na adaptação com a realidade local, observava-se a indisponibilidade de alguns equipamentos e a necessidade de diminuir o distanciamento entre as aulas teóricas e as necessidades das empresas.

Sobre a instalação do Senai em um local próprio, verificou-se que nos relatórios da Direção Regional já havia, desde 1944, a pretensão de construir, com recursos próprios as escolas de Curitiba, Londrina e Ponta Grossa e "[...] a demora desta última foi devido à promessa da prefeitura local doar o terreno, o que não aconteceu [...]" por motivos desconhecidos (TREVIZAN, 1995, p. 50).

No ano relatado, da pretensão da construção do Senai, o prefeito da cidade era o Sr. Albary Guimarães, o qual governou Ponta Grossa por 12 anos. Na época do seu governo, as dívidas do município eram grandes, talvez este seja um dos fatores da "promessa não cumprida", pois, sem apoio do Governo Federal o prefeito encontrava dificuldades em diversos setores estruturais do município como: nas ampliações das redes de água e esgoto da cidade, as quais estavam comprometidas e, naquele governo, não puderam ser concluídas.

$\mathrm{Na}$ indústria do ramo madeireiro, no mesmo ano de início do Senai, fundou-se em Ponta Grossa a Indústria Wagner, parceira do Senai na acolhida dos alunos do CAO.

No contexto político, no ano seguinte, o

[...] presidente Getúlio Vargas veio à Ponta Grossa em 1944. Era sua segunda visita, pois já estivera aqui quando da Revolução de 1930, passando alguns dias, [...] Foi, em Ponta Grossa, que recebeu a notícia de que deveria seguir para tomar posse no governo federal. Foi quando Ponta Grossa passou ser conhecida como a "Capital Cívica do Paraná". Em janeiro de 1945, Albary Guimarães renunciou ao cargo (CASTILHO, L.C. http://plantaodacidade.com.br/). 
Getúlio Vargas estava em Ponta Grossa quando recebeu o telegrama da Junta Militar, colocando a Presidência à sua disposição. Dessa forma, partiu para o Rio de Janeiro acompanhado pelos soldados do Quartel de Uvaranas, chegando lá, assumiu o cargo de Presidente Provisório do Brasil e ficou nesse cargo por 15 anos.

Em 1946, os cursos voltados à aprendizagem dos menores ficaram fragilizados, tendo em vista que, os industriais reivindicavam uma formação mais imediata e alegavam indisponibilidade da indústria em fornecer postos de trabalhos para esses menores. Havia

[...] dificuldade das indústrias cuidarem disciplinarmente dos alunos, pois ficavam sem instrutor após as demonstrações das tarefas, já que cada instrutor deveria se deslocar para outras indústrias para instruírem outros alunos durante a jornada de trabalho nas indústrias e também o problema da não fiscalização do Ministério do Trabalho pelo cumprimento do pagamento de menores aprendizes, o que poderia causar o desestímulo da aprendizagem (Casa da Memória- autor desconhecido).

Assim, para atender os desejos da classe industrial, o Ministério do Trabalho começou a intervir, a fim de que os aprendizes pudessem, de fato, ingressa no ambiente industrial. A partir do Decreto-lei ${ }^{\circ}$ 9.576, de 12 de agosto de 1946 as empresas

[...] industriais foram obrigadas a empregar e matricular nas escolas mantidas pelo Senai um número de aprendizes equivalente a $5 \%$, no mínimo, e $15 \%$ no máximo, dos operários cujos ofícios demandassem formação profissional (CUNHA, 2000, p. 50).

Diante da obrigatoriedade e fiscalização do Ministério do Trabalho, as empresas de Ponta Grossa, como as demais empresas brasileiras tiveram que se adequar e dar continuidade ao desenvolvimento do CAO.

Nesse momento é que começava, realmente a se pensar num espaço próprio. "[...] Para isso, foram mobilizados empresários a fim de exigirem da FIEP e do DR do Senai" (Casa da Memória, autor desconhecido) os recursos provenientes para tal construção.

Em 1946, o professor Gobbo participou de um treinamento em São Paulo, com duração de seis meses, na área de siderurgia e mineração. Após, foi nomeado como instrutor chefe do Senai de Siderópolis, em Santa Catarina e, em 1954 foi transferido novamente para Ponta Grossa; sendo sua função primordial "[...] criar um serviço de aprendizagem no próprio emprego, seguindo uma relação de ofícios com duração prédeterminada e organizada" (Casa da Memória, autor desconhecido).

Diante disso, verifica-se que os ambientes para a construção e instalação do Senai foram sincréticos, no sentido de afirmação estrutural. Já para o trabalhador da sociedade capitalista, incutidos no ensino profissionalizante; este, ao ser lançado no mercado de trabalho, possuía um caráter mediador e passava a ser parte do produto de seu serviço tornando-se venda da sua força de trabalho e garantindo sua manutenção na sociedade.

As políticas de gestão adotadas para a concretização dessa instituição, aparentemente, tinham num caráter compensatório e centralizador voltado aos interesses da sociedade capitalista. Sendo assim,

[...] os cursos de formação profissional acabam por reproduzir a mesma pedagogia da fábrica, que consiste basicamente em promover $\mathrm{o}$ aprendizado de um conjunto de operações parciais, muitas vezes desconexas, sem que se possibilite a apreensão de uma tarefa em sua 
totalidade, considerando inclusive a ciência que incorpora (KUENZER, 1988, p.22).

É importante refletir na criação de mecanismos que favoreçam a participação efetiva da sociedade nas decisões adotadas bem como, a aproximação com a práxis. Isso parece importante quando se pensa em formação de sujeitos autônomos que querem aprender, não de forma desconexa, mas com a compreensão do todo, sendo capazes de contribuir na transformação social.

Nesta pesquisa, foi possível verificar que as políticas instauradas, em sua maioria, estavam a serviço da manutenção e garantia mínima para sobrevivência da classe trabalhadora em face da relação capitalista antagônica entre capital e trabalho. No entanto, as escolas profissionais, por si só, não são a causa da pseudoconsciência dos sujeitos e nem é a única instituição escolar a perpetuar este modelo educacional.

Referências:

BOLOGNA, I. Roberto Mange e sua obra. [S.I.]:Unigraf, 1980.

Casa da Memória - Autor desconhecido.

CASTILHO,L.C.http://www.plantaodacidade.com.br/governo/prefeitos.htm\#Albari

Guimarães. Acesso em: 16 jun.2011.

CHAVES, N. B. Do Centro Commercio e Indústria ao Selo Social. Ponta Grossa. Editora: UEPG, 2006.

CHAVES, N. B. Do Centro Commercio e Indústria ao Selo Social. Ponta Grossa. Editora: UEPG, 2006.

CHAVES, N.B; BREMBATTI, K. Desenvolvimento \& Sociedade: ACIPG 85 anos de histórias. UEPG. Ponta Grossa, 2008.

CUNHA, L.A. O Ensino Profissional na Irradiação do Industrialismo. São Paulo: Ed. UNESP, 2000.

DIÁRIO DOS CAMPOS, 18 de fevereiro de 1937.

DITZEL, C. H. M. Imaginários e representações: o integralismo nos Campos Gerais (1932-1955). Ponta Grossa: Editora UEPG, 2007.

DITZEL, C.H.M; SAHR, C.L.L. (Orgs.) Espaço e Cultura: Ponta Grossa e os Campos Gerais. Ponta Grossa: Editora UEPG, 2001.

GOMEZ, C. M. et al. Trabalho e Conhecimento: Dilemas na Educação do trabalhador.3 ed. São Paulo: Cortez, 1995.

KUENZER, A.Z. Educação e Trabalho: questões teóricas. Educação e Trabalho. CRHFACED- UFBA: Fator Editora, 1988. 
KUENZER, A.Z. Pedagogia da Fábrica: as relações de produção e educação do trabalhador. 6ed. São Paulo, Cortez, 2002.

LOPES, S. Uma saga da criatividade brasileira. Rio de Janeiro: SENAI - DN, 1982.

MARTINS, R. História do Paraná. 3. ed. Curitiba: Guairá,1969.

NASCIMEnTO, M. I. M. A Primeira Escola de Professores dos Campos Gerais- PR. Ponta Grossa: Editora UEPG, 2008.

O Progresso, 20 de julho de 1912.

OLIVEIRA, D. de. Urbanização e Industrialização no Paraná. Curitiba: SEED, 2001.

PADIS, P. C. Formação de uma economia periférica: o caso do Paraná. 2.ed. Curitiba: IPARDES, 2006

SAVIANI, D. O trabalho como princípio educativo frente às novas tecnologias.In: FERRETTI, C. J. et al. Novas tecnologias, trabalho e educação: um debate multidisciplinar. Petrópolis: Vozes,1994.

SILVA, E. A. Energia elétrica em Ponta Grossa. In: Espaço e Cultura. Ponta Grossa e os Campos Gerais. Ponta Grossa: UEPG, 2001, p.91-98.

TREVIZAN, A. T. SENAI - Paraná- 50 anos. Curitiba: Champagnat, 1995.

WANKE, E. T. O vôo da pombinha. Ponta Grossa, 1964 (folheto).

${ }^{3}$ Notas

1 "O ano de 1731 marca o início do tropeirismo no Paraná, que se prolonga até fins do século XIX com o advento das estradas de ferro e de rodagem" (TREVIZAN, 1995, p.47).

${ }^{2}$ Descendentes de alemães que moravam na Rússia.

${ }^{3}$ A Estrada do Viamão é caracterizada pela união da cidade de Vacaria, no Rio Grande do Sul, aos Campos Gerais na época do tropeirismo. Ao longo deste caminho, foram formados pequenos lugarejos que, mais tarde, deram origem às cidades de Jaguariaíva, Piraí do Sul, Castro, Ponta Grossa, Palmeira, Lago, Rio Negro e Lapa. (MARTINS, 1969). Lugares que compõem a região dos Campos Gerais.

${ }^{4}$ Dormentes são as peças de madeira, que servem de sustentação para os trilhos das estradas de ferro.

${ }^{5}$ A construção da ferrovia iniciou em 1893 e em pouco mais de dez anos estava concluída. Se levarmos em conta, as poucas condições da época, pode-se considerar que foi um processo rápido.

${ }^{6}$ Atual Associação Comercial, Cultural, Agrícola e Industrial de Ponta Grossa (ACCIPG). 
${ }^{7}$ A Cervejaria Adriática se destacou como a maior indústria pontagrossense até meados do século $\mathrm{XX}$, as maquinarias trazidas da Alemanha e as técnicas europeias introduzidas na fábrica, conceituavam-na como referência entre os industriais locais. Henrique Thielen, ganha destaque na vida política do município até então composta por famílias tradicionais que colonizaram a região. Em 1945, foi vendida para a Companhia Antarctica Paulista e em 1990 seu prédio foi demolido (DITZEL,2007).

${ }^{8}$ Consideramos como derivados da madeira: fabricação de papel, móveis, entre outros. Sobre as serrarias existentes nos Campos Gerais, consultar LANGE (1922).

${ }^{9}$ Neste período, exercendo o cargo de Diretor Regional.

${ }^{10}$ Flausino Mendes da Silva foi "[...] engenheiro civil pela Escola Politécnica da Universidade do Rio de Janeiro, exerceu cargos administrativos no Paraná: Diretor Superintendente da Rede de Viação Paraná- Santa Catarina; Diretor do Departamento de Águas e Energia Elétrica e passou pela valiosa experiência do CEFESP" (LOPES, 1982, p.72).

${ }^{11}$ Esses cursos funcionaram até 1963.

${ }^{12}$ Havia também o CAI - Curso de Aspirante à Indústria, onde os alunos eram selecionados diretamente pelo Senai (CUNHA, 2000). No entanto, neste período inicial, não há registro destes no município de Ponta Grossa, PR.

${ }^{13}$ Não há evidência em qualquer documento sobre a forma de escolha: se era por votação, indicação ou outra.

${ }^{14}$ Estas carteirinhas de controle são utilizadas até hoje, porém, o preenchimento é feito por uma pessoa do setor pedagógico que encaminha as notas e faltas dos alunos para as empresas. Ou seja, o processo é contrário, porém, ainda vigente.

15 O Senai criou uma lista dos "ofícios qualificados nos diversos grupos industriais". Detalhadamente sobre estes, consultar: Cunha (2000, p. 51 - 53).

${ }^{16}$ A inauguração deste espaço próprio se deu em 08 de Março de 1963, sobre a denominação de Centro de Formação Profissional Flausino Mendes, localizado no bairro Jardim América. Durante mais de 20 anos o Senai de Ponta Grossa, funcionou em espaços locados ou cedidos.

Recebido em março/2012

Aprovado em setembro/2012 